\title{
Erratum to: Ringing the changes in evaluation of urogenital prolapse
}

\author{
Sushma Srikrishna • Dudley Robinson • Linda Cardozo
}

Published online: 3 March 2011

(C) The International Urogynecological Association 2011

Erratum to: Int Urogynecol J

DOI 10.1007/s00192-010-1253-7

Owing to an oversight by the authors, this article contained an acknowledgement of a research grant from a pharmaceutical company. The authors regret this error and would like to make it clear that no such support was received.

The online version of the original article can be found at http://dx.doi. org/10.1007/s00192-010-1253-7. 